\title{
Gender Differences in Recognition for Group Work
}

\author{
Heather Sarsons*
}

November 4, 2017

\begin{abstract}
How is credit for group work allocated when individual contributions are not perfectly observed? Do demographic traits like gender influence the allocation of credit? Using data from academic economists' CVs, I test whether coauthored and solo-authored publications matter differently for tenure for men and women. Because coauthors are listed alphabetically in economics, coauthored papers do not provide specific information about each contributor's skills or ability. Solo-authored papers, on the other hand, provide a relatively clear signal of ability. I find that men are tenured at roughly the same rate regardless of whether they coauthor or solo-author. Women, however, become less likely to receive tenure the more they coauthor. The result is most pronounced for women coauthoring with men and less pronounced among women who coauthor with other women. I contrast economics with sociology, a discipline in which coauthors are listed in order of contribution, and find that when contributions are made clear, men and women receive equal credit for coauthored papers.
\end{abstract}

${ }^{*}$ I especially thank Roland Fryer, Claudia Goldin, Larry Katz, David Laibson, and Amanda Pallais for their guidance and encouragement. I also thank Mitra Akhtari, Amitabh Chandra, John Coglianese, Oren Danieli, Ellora Derenoncourt, Florian Ederer, Raissa Fabregas, Nicole Fortin, Peter Ganong, Edward Glaeser, Sara Lowes, Eduardo Montero, Alex Segura, Nihar Shah, Peter Tu, Justin Wolfers, and participants at SOLE 2016, the Early Behavioural Economics Conference, the Harvard Business School Gender Initiative, and the Harvard Inequality Seminar for helpful comments and suggestions. This paper is intentionally soloauthored. 


\section{Introduction}

How do employers infer workers' productivity under uncertainty? In many workplaces, employers must make hiring and promotion decisions under incomplete information or in the face of subjective productivity measures (Prendergast, 1999; MacLeod, 2003). Employees working in teams is an example of this. Unless employers can perfectly observe each worker's contribution to the team's output, employers must decide how to allocate credit without having full information as to what each worker did. This is of increasing relevance as many organizations rely predominantly on group work for production ${ }^{1}$.Yet there is little empirical evidence on how credit for group work is allocated and whether demographic characteristics such as gender play a role.

In this paper, I test whether uncertainty over an individual's contribution to a project leads to differential attribution of credit that contributes to the gender promotion gap. In many industries, women are not only hired at lower rates than men are, they are also promoted at lower rates. Blau and DeVaro (2007), for example, find that across jobs, women are less likely to be promoted than men conditional on worker's performance and ability ratings. In the UK, female managers are nearly $40 \%$ less likely to be promoted than male managers (Elmins et al. 2016). A significant portion of the promotion gap remains unexplained even after accounting for factors such as productivity, personality and behavioural differences (such as competition aversion), and fertility preferences ${ }^{2}$.

I specifically look at tenure decisions within academia, an ideal setting for two reasons. First, there is a large tenure gap between men and women, over 30\% of which can not be explained by observable productivity differences or family commitments (Ginther and Kahn, 2004). Second, disciplines within academia differ in their treatment of authorship. This provides variation in the clarity of signals that employers receive. For example, in economics, coauthors are listed alphabetically, making it difficult to discern who did what on a coauthored paper. Solo-authored papers, on the other hand, provide a clear signal of the author's ability. In sociology, authors are listed in order of contribution, making both coauthored and solo-authored papers clear signals.

I primarily use data from economists' CVs to track individuals' career trajectories and compare whether the trajectory is different for individuals who coauthor versus soloauthor, and whether there is a difference by gender. I then contrast economics with sociol-

\footnotetext{
${ }^{1}$ Lazear and Shaw (2007), for example, report that the share of large U.S. firms whose workers predominantly work in teams rose from $27 \%$ to $78 \%$ between 1987 and 1996

${ }^{2}$ There is a large literature documenting gender differences in productivity, attitudes toward different types of work, and family choices. See, for example, Niederle and Vesterlund (2007), Antecol et al. (2016), Ceci et al. (2014), and Ginther and Kahn (2004).
} 
ogy to test whether there is a smaller unexplained promotion gap in academic disciplines where it is easier to discern an author's specific contribution.

Within economics, I find that men and women who solo-author most of their work have similar tenure rates conditional on a proxy for the quality of papers. However, an additional coauthored paper is correlated with an $8 \%$ increase in tenure probability for men but only a $2 \%$ increase for women. This gap is significantly less pronounced for women who coauthor with women, suggesting that the attribution of credit is related to the gender mix of coauthors. Furthermore, a man who coauthors is no less likely to receive tenure than a comparable man who solo-authors even though there is presumably more uncertainty as to how much work he did. In sociology, women who coauthor are as likely to receive tenure as men who coauthor, suggesting that it is the uncertainty contained in the alphabetical ordering of authors that disproportionately hurts women.

To ensure that I am not picking up on ability differences between men and women, I control for the quality of papers using both journal rankings and citations, allowing for a comparison of men and women with similar research portfolios. The results are also robust to including other individual-level controls such as length of time to tenure and the seniority of one's coauthors, as well as tenure year, tenure institution, and primary field fixed effects.

While I cannot pinpoint a specific mechanism that explains why coauthoring has lower returns for women, I rule out several standard explanations. The difference in credit does not appear to be due to women's own behaviour: they are not especially likely to coauthor with senior or high-ability faculty, nor do they present their coauthored work less. The empirical patterns are also inconsistent with taste-basted discrimination.

The remainder of the paper is organized as follows. Section 2 describes the data and shows that a tenure gap exists between male and female economists. In Section 3, I show that the tenure gap is driven by women having a lower probability of tenure for each additional coauthored paper than men. I then contrast economics with sociology to see how results change based on the quality and clarity of the signal. I show that the results are robust to using different journal rankings and definitions of tenure. In Section 4, I test four theories that might explain this relationship and argue that none can fully explain the observed empirical patterns. I look at how the relationship between coauthoring and tenure has changed over time and by school in Section 5 and conclude in Section 6. 


\section{Data}

To examine the relationship between paper composition and tenure, I construct a dataset using the CVs of economists who came up for tenure between 1985 and 2014 at one of the top 30 U.S. PhD-granting universities ${ }^{3}$. The academic progression documented in the CVs makes it possible to evaluate the relationship between the individual's research output and career progression. I can then compare the degree of collaborative work and reward for that work, and compare these results for men versus women.

\subsection{Sample Selection and Data Overview}

I include only PhD-granting institutions in the sample so that, as much as possible, I am comparing individuals facing similar tenure requirements. For example, liberal arts colleges place greater weight on teaching ability for tenure, something that I cannot measure. I exclude business and public policy schools for similar reasons. Many business schools require professors to write cases, for example, and it is not clear how this factors into tenure decisions. It is reasonable to assume that the top 30 economics departments in the U.S. emphasize research which is measured by the number and quality of papers one produces.

One problem in collecting tenure information is that the CVs of individuals who went up for tenure, were denied it, and left to industry or government are difficult to find, leading to a sample selection problem. To deal with this issue, I was able to collect historical faculty lists from 17 of the 30 schools and locate over $90 \%$ of faculty who had ever gone up for tenure at these 17 institutions. For the remaining 13 schools, I looked at the top 75 U.S. institutions, the top 5 Canadian institutions, and the top 5 European institutions to locate anyone who went up for tenure at a top 30 U.S. school and then moved to another institution. I also checked economists' CVs at the major Federal Reserve Boards and other large research institutes, such as Mathematica, in the U.S. While there might still be a sample selection problem, I show in Section 3.3.1 that the results are robust to using only the sample for which I have historical faculty lists.

From individuals' CVs, I code where and when they received their PhDs, their employment and publication history, and their primary and secondary fields. When looking at the relationship between publications and tenure in the main analysis, I only include papers that were published up to and including the year an individual goes up for tenure. Forthcoming papers and book chapters are not included in the paper count, but I later include such papers as a robustness check.

\footnotetext{
${ }^{3}$ The list of institutions included can be found in Appendix A
} 
I primarily use the $2015 \mathrm{RePEc} / \mathrm{IDEAS}$ ranking of economics journals to control for the quality of a person's publications. For this, I take the top 85 journals and give the top journal a score of 86 . The lowest quality journal has a score of two. Any journals below this are given a score of one ${ }^{4}$. Finally, I include current citations of pre-tenure papers as a control variable. These citations were scraped from Google Scholar.

I supplement this dataset with results from a survey designed to measure individuals' beliefs about the returns to various types of papers. The survey also contains information on how frequently individuals present their papers. The exact questions and nature of the survey are discussed in greater detail in Section 4.

\subsection{Construction of Tenure}

To determine whether someone received tenure, I follow the guidelines on each school's website (as of 2015) as to when tenure decisions are made. The majority of schools require faculty to apply for tenure 7 years after their initial appointment. I therefore consider years 6-8 to be the "tenure window" in which someone applies for tenure to account for people who go up for tenure early or late (because of a leave of absence, for example). I assume that an individual is denied tenure if $\mathrm{s} /$ he moves to a university ranked 5 positions below the initial institution during the tenure window. Similarly, I assume that an individual is denied tenure if he moves from academia to industry during the tenure window. Defining tenure in this way accounts for the fact that some people switch institutions 2-3 years after their initial appointment, not because they were denied tenure but for personal preferences, and that some people might choose to move to a comparable school around the time of tenure even though they were offered tenure at their original institution. For example, someone who moves from MIT to Harvard after 7 years was presumably offered tenure at MIT but chose to move to Harvard for other reasons.

As mentioned, a person who moves 5 or fewer years after his or her initial appointment is not assumed to have been denied tenure since $\mathrm{s} /$ he moved before the tenure window starts. If someone moves before the tenure window, I use the second institution they were at to determine tenure. For example, if a person's first job is at University A but s/he moves to University B after three years, I use University B as the tenure institution but do not start the tenure clock over. In this example, I would look 3-5 years after the individual starts at University B (that is, 6-8 years after the initial position) to determine whether the individual received tenure. If a person moves from an academic institution into industry before the tenure window, I exclude them from the sample.

\footnotetext{
${ }^{4}$ Less than $10 \%$ of papers are published in journals not included in the RePEc/IDEAS ranking.
} 


\subsection{Summary Statistics}

Table 1 presents summary statistics of the data. Approximately $70 \%$ of the full sample received tenure, but this masks a stark difference between men and women. Only $52 \%$ of women received tenure while $75 \%$ of men did.

Total Papers, Solo-authored, and Coauthored are the number of papers in each group that an individual had published by the time of tenure. These publication counts do not include books or book chapters. Papers published in non-economics journals (such as a political science journal) are included but receive a ranking of 1 (the lowest ranking). The results are robust to excluding publications in non-economics journals.

There is no statistically significant difference in the number of papers that men and women produce. Panel B looks at differences in the quality of papers. Men are no more likely to publish their papers in "Top 5" journals (American Economic Review, Econometrica, Journal of Political Economy, Quarterly Journal of Economics, and The Review of Economic Studies) than women are. The only statistically significant productivity difference is that men tend to publish their coauthored papers in slightly higher-ranking journals. I therefore control for the quality of papers, measured as the average journal ranking and average citations, throughout the analysis.

Panel C displays differences in coauthoring patterns between men and women. Total Unique CAs is the number of unique coauthors an individual has had by tenure. Men and women have roughly the same number of coauthors and women are no more likely to coauthor with senior faculty than men are. The only significant difference in coauthorship is that $26 \%$ of women's coauthors are other women whereas only $11 \%$ of men's coauthors are women.

\section{Empirical Strategy and Results}

To understand how credit for group work is allocated, I correlate paper composition with tenure while controlling for individual-level characteristics as well as school, year, and primary field fixed effects. While an additional solo-authored paper is associated with the same increase in tenure probability for men and women, an additional coauthored paper is correlated with a larger increase in tenure probability for men than for women.

After establishing this result, I contrast economics with sociology, a discipline in which authors are listed according to contribution rather than alphabetically. In this case, an author's contribution is clear and there is no longer a gender difference in the relationship between coauthored work and tenure. Taken together, these results suggest that the un- 
certainty created by alphabetically ordering authors leads to women receiving less credit and contributes to the gender promotion gap.

\subsection{Main Results}

I show three main results. I first establish that a significant tenure gap exists between men and women. I then show that the gap becomes more pronounced the more women coauthor, and that women who solo-author all of their papers have comparable tenure rates to men. Finally, I show that the gender of a woman's coauthor matters. Women who coauthor with other women do not suffer a coauthor penalty, providing evidence that women receive less credit for joint work than men do, whether warranted or not.

\subsubsection{The Tenure Gap}

Figure 1 plots the lines of best fit from estimating

$$
T_{i f s t}=\beta_{1} \text { TotPaper } s_{i}+\gamma^{\prime} Z_{i}+\theta_{f}+\theta_{s}+\theta_{t}+\epsilon_{i f s t}
$$

separately for men and women using OLS. The dependent variable, $T_{i f s t}$, is an indicator that individual $i$ in field $f$ at school $s$ receives tenure in year $t$. TotPaper $s_{i}$ is the number of papers (both coauthored and solo-authored) individual $i$ has at the time he or she went up for tenure. The vector of individual-level controls, $Z_{i}$, includes average journal rank, total citations, the number of years it took $i$ to go up for tenure, and the number of coauthors on papers. Tenure institution $\left(\theta_{s}\right)$, tenure year $\left(\theta_{t}\right)$, and field fixed effects $\left(\theta_{f}\right)$ are also included as tenure standards likely vary over time and by field and department.

The figure shows that a significant tenure gap exists between men and women even after controlling for productivity, primary field, tenure institution, and tenure year. While an additional paper is correlated with a roughly 4 percentage point increase in tenure probability for both men and women, women are consistently 17 percentage points less likely to receive tenure than men conditional on having written the same number of papers of similar quality. The corresponding estimates for equation 1 using a probit model are presented in Column 1 of Table 2.

\subsubsection{The Tenure Gap and Paper Composition}

If solo-authored papers provide a clear signal of ability, we would expect men and women to benefit similarly from an additional solo-authored paper, conditional on paper quality. 
Figure 2 plots the coefficients $\hat{\beta}_{1}$ and $\hat{\beta}_{1}+\hat{\beta}_{2}$ from

$$
T_{i f s t}=\beta_{1} S_{i}+\beta_{2}\left(f e m_{i} \times S_{i}\right)+\beta_{3} C A_{i}+\beta_{4}\left(f e m_{i} \times C A_{i}\right)+\delta_{1} f e m_{i}+\gamma^{\prime} Z_{i}+\theta_{f}+\theta_{s}+\theta_{t}+\epsilon_{i f s t}
$$

where $S_{i}$ and $C A_{i}$ are the number of solo-authored and coauthored papers an individual has at the time of tenure. Here we see a large tenure gap between men and women who have few solo-authored papers. However, the gap converges as women write more solo-authored papers. It seems that the signal from the solo papers begins to outweigh the employer's prior, which is consistent with a model in which employers start with lower beliefs about women and update as they receive clear signals about a woman's ability.

If coauthored papers are an unclear signal of ability, an employer must make a judgment call as to how much each coauthor contributed to the paper which could lead to differential attribution of credit. Indeed, we see tenure rates diverging in Figure 3, which plots the relationship between an additional coauthored paper and tenure $\left(\hat{\beta}_{3}\right.$ and $\hat{\beta}_{3}+\hat{\beta}_{4}$ from equation 2 ). While an additional coauthored paper helps both men and women, men benefit much more than women, suggesting that coauthored work is typically attributed to men. Columns 2 and 3 of Table 2 show the corresponding coefficients for equation 2, estimated using a probit model. From these estimates, men's tenure rates increase by 7.7 percentage points when they produce a coauthored paper whereas women's increase by 2 percentage points.

The results are summarized in Figure 4. This figure plots the relationship between the fraction of an individual's papers that are solo-authored, controlling for the total number of papers, citations, journal quality, number of coauthors, and tenure institution, year, and field fixed effects. For men, it does not matter if one coauthors or solo-authors: tenure rates are comparable conditional on the quality of papers. Women who write all of their papers alone have similar tenure rates to men. However, women who coauthor all of their papers have an approximately $40 \%$ tenure rate, substantially lower than that of men who coauthor all of their papers ( $75 \%$ ). The slope for women is 0.37 and is statistically significant at the $5 \%$ level (s.e. $=0.167)$.

\subsubsection{Does Coauthor Gender Matter?}

The probability of receiving tenure is not lower for all women who coauthor. In Table 3, I categorize coauthored papers into those written with only men, only women, or a mix of men and women: 


$$
\begin{aligned}
T_{i f s t}= & \beta_{1} S_{i}+\beta_{2}\left(\text { fem }_{i} \times S_{i}\right)+\beta_{3} \text { CAmale }_{i}+\beta_{4}\left(\text { fem } \times C \text { Amale }_{i}\right)+\beta_{5} \text { CAmix }_{i} \\
& +\beta_{6}\left(\text { fem } \times \text { CAmix }_{i}\right)+\beta_{7} \text { CAfem }_{i}+\beta_{8}\left(\text { fem }_{i} \times \text { CAfem }_{i}\right)+\beta_{9} \text { fem }_{i} \\
& +\gamma^{\prime} Z_{i}+\theta_{f}+\theta_{s}+\theta_{t}+\epsilon_{i f s t}
\end{aligned}
$$

As before, $S_{i}$ is the number of solo-authored papers individual $i$ has. CAfem $i$ is the number of coauthored papers individual $i$ has in which all of the coauthors are female. Similarly, $C A$ male $_{i}$ is the number of papers $i$ has in which all of the coauthors are male and $C A m i x_{i}$ is the number of papers $i$ has in which the coauthors consist of men and women.

The estimated coefficients on the interaction terms show that women receive almost no marginal benefit from producing a coauthored paper with a man but receive some benefit when there is either a mix of male and female coauthors or only female coauthors. The point estimates suggest that an additional paper that a woman writes with a mix of men and women improves tenure chances by $3.6 \%$ and an additional paper with other women improves tenure probability by $9.2 \%$, the same increase a man receives. While the estimates are imprecise due to sample size, I can rule out that an additional coauthored paper with a woman has the same effect as an additional coauthored paper with a man. The estimates are robust to including all of the control variables discussed earlier.

These results imply that the differential attribution of credit arises when signals are noisy and that men tend to disproportionately benefit from this noise. If a woman coauthors with a woman, credit is given to both of them. However, when a woman coauthors with a man, the man receives the bulk of the credit, suggesting that employers rely on gender in some way to infer ability or effort. However, this does not mean that the employer is acting sub-optimally or is biased against women. I explore possible explanations in Section 4. First, though, I test whether removing the noise from a signal reduces the gender gap in credit.

\subsection{Testing Against Other Coauthoring Conventions}

If the uncertainty contained in a "coauthored" signal is contributing to the gender gap, clearly stating an individual's role on a project would alleviate this problem. I test whether this is true by looking at sociology, where authors are listed by order of contribution. This removes uncertainty over each author's contribution to the paper. Of course it should be noted that sociology is not the perfect comparison as many other factors differ across the two disciplines, including the fraction of women in each discipline. Still, the results shed 
light on whether the uncertainty contained in coauthored papers in economics contributes to a promotion gap.

The sociology sample consists of randomly sampled faculty at the top 20 sociology PhD-granting departments in the U.S ${ }^{5}$. There are 250 sociologists in the sample, $40 \%$ of whom are female. Summary statistics are presented in Table 4 . There is no statistically significant difference between men and women's tenure rates (with the mean tenure rate being $76 \%$ ) although men seem to publish more solo-authored articles than women.

To test whether men and women are treated differently, I reestimate equation 2 but include measures of the number of papers that researcher $i$ is first author on. The results are presented in Table 5. I include the number and fraction of papers a researcher is first author on in Columns 1 and 2 respectively, along with female dummy interaction terms.

Being first author on a paper is correlated with a $5 \%$ increase in tenure probability for both men and women. Importantly, women are not penalized for coauthoring. Results are somewhat noisy due to the small sample, but the coefficient on the female/total coauthored papers interaction term is close to zero, indicating that women receive credit for their work when their contribution to a project is clear.

\subsection{Robustness Checks}

One may be concerned that the results are a product of the types of productivity measures used or of missing data. In this section, I show that the results are robust to using only the sample for which I have no missing observations, to using different journal rankings, and to accounting for papers published shortly after tenure.

\subsubsection{Attrition}

The results might be biased if the sample excludes individuals who are denied tenure and go into industry, government, or other institutions where I do not observe them. This would be particularly problematic if men who go to industry after being denied tenure disproportionately coauthored their papers. If this is true, I would be overestimating the benefit of coauthoring for men. I would have a similar problem if women who go to industry after being denied tenure typically wrote solo-authored papers.

As discussed in Section 2.1, I attempted to find such individuals by searching institutions outside of the top 30 U.S. schools, federal reserves, and other research institutes. Doing so certainly does not guarantee I found everyone who went up for tenure, though.

\footnotetext{
${ }^{5}$ Ranking from U.S. News Education
} 
To allay concerns about sample selection, I run the analysis on the sample for which I received historical faculty lists. These lists allow me to track who went up for tenure and find them even if they left academia. The results, presented in Column 1 of Table 6, do not change when run on the sample for which there should be very few missing observations.

\subsubsection{Journal Rankings}

While the economics profession largely agrees on what the "top" journals are, rankings of field journals or lower-tier journals have changed over time and might be disputed. Furthermore, including an average journal ranking could mask differences in the rankings of solo and coauthored papers between men and women. In Columns 2 and 3 of Table 6, I attempt to account for this by using two alternative journal ranking metrics.

In Column 2, I separately include the average ranking of one's solo and coauthored papers. In addition, I convert each journal ranking into its "AER equivalent" where each raw publication is converted into its number of American Economic Review-equivalent papers. This has the advantage of standardizing the journal quality measure, and for allowing different distances between paper ranks. For example, in the RePEc/IDEAS ranking, Econometrica is one ranking below the AER. Using the AER-equivalent measure, a paper in Econometrica is nearly equivalent to having a paper in the AER. A paper in many of the top field journals is equivalent to having published 0.15-0.2 papers in the AER. For details on the methodology and the ranking, see Kalaitzidakis, Mamuneas, and Stengos (2003). Again, the results are unchanged.

In Column 3, I allow journal rankings to change over time. I use historical rankings of economics journals (drawn from Laband and Piette, 1994, and combined with current rankings) and match each paper a person publishes with its journal ranking at the time it was published. In Column 3, the variable Avg Journal Rank is then the average rank of an individual's papers, measured using the historical rankings. Using these rankings accounts for journals moving in rank over time as well as new journals being added. Again, the results do not qualitatively change. An additional coauthored paper is associated with a 7.7 percentage point increase in tenure probability for men but only a 2.2 percentage point increase for women. In section 4, I also separate papers into "Top 5s" and "non-Top $5 s^{\prime \prime}$.

\subsubsection{Tenure Definition}

In the main analysis, I only consider papers that were published up to and including the year that an individual goes up for tenure. If an individual goes up for tenure in 1995, for 
example, papers published in 1996 are not included in the paper count even though they may have been "revise and resubmits" at the time of tenure. This could affect the results if men who coauthor have several promising unpublished papers at the time of tenure but women who coauthor do not, in which case I am not actually comparing people with similar publication records. In Columns 4 and 5 of Table 6, I include papers that are published one and two years after a person's tenure year in the paper count variables. The results do not change: women continue to benefit less from coauthored papers than men do.

\section{Channels}

There are many possible explanations for the above findings, not all of which can be tested with these particular data. Here I shed light on four standard and testable channels: ability-based sorting, preference-based sorting, women not claiming credit for their work, and taste-based discrimination. The empirical patterns are inconsistent with all of the proposed explanations, most of which would have suggested that a woman's own behaviour leads her to receive less credit for joint work.

\subsection{Ability-Based Sorting}

Employers might rationally deny women who coauthor tenure if individuals sort such that only lower ability women coauthor with men. This could arise for several reasons. For example, if coauthoring lowers the cost of producing a paper, but women know that they receive less credit for papers, high ability women might forego the cost savings and choose to work alone. They know they can produce high quality papers by themselves and send the employer a clearer signal of their ability. However, if low ability women can only produce high quality papers with the help of a high ability man, they might coauthor even if they receive less credit. High ability men will agree to coauthor with them if it reduces the cost of the paper without reducing the quality. Employers would then know that any woman coauthoring with a man is lower ability.

A simple sample of worker sorting and promotion is presented in Appendix B. The framework provides intuition for when women of different ability types would choose to coauthor with men. If women do not know that they receive less credit for coauthoring, we should see assortative matching. Men and women of the same ability level will collaborate, making the decision to deny coauthoring women tenure sub-optimal. If women do know that they receive less credit, high ability women will opt to work alone while, 
under certain conditions, low ability women will coauthor. In this case, it is optimal for an employer to tenure coauthoring women at lower rates than men.

In what follows, I test whether women anticipate receiving less credit and consequently sort accordingly. To do so, I first present survey evidence suggesting that women do not know that the returns to coauthoring are lower than solo-authoring. I then show that women do receive some credit for papers that publish well, suggesting that employers believe that there might be some assortative matching. Finally, I provide evidence that even when women tend to work with men who are slightly higher ability than themselves this unequal match does not explain the gender gap in tenure.

\subsubsection{Survey Evidence on Knowledge of Returns to Coauthoring}

If women know that their returns to coauthoring with men are low, it is plausible that high ability women would choose to solo-author or only work with other women. Here I test whether women anticipate receiving less credit for collaborative work. However, it is first worth noting that the results presented in Section 3.1.3 show that women have a nearly $0 \%$ return to coauthoring with a man. If women know the true returns to coauthoring, any woman, regardless of ability, should be hesitant to collaborate (see Appendix B for details). The fact that we see women coauthoring with men already implies that women misjudge the true returns to coauthoring.

I test whether women know the true returns to coauthoring using a survey conducted with economists currently working at the top 35 U.S. economics departments. The survey was sent to all professors, regardless of rank, at these institutions and received an $32 \%$ response rate. The gender composition of the sample is representative of the profession today, with 89 respondents being female and 300 being male. In the survey, economists were asked the following question:

Suppose a solo-authored AER increases your chance of receiving tenure by 15\%. For each of the following, please give an estimate of how much you think the described paper would increase your chance of receiving tenure.

Respondents then go through five types of papers (coauthored AER, coauthored AER with senior faculty, coauthored AER with junior faculty, solo-authored top field, and coauthored top field) and record their beliefs about the returns to these papers ${ }^{6}$.

\footnotetext{
${ }^{6}$ I did not ask respondents about paper coauthored with men/women so that they would not be primed to think about gender
} 
In Table 7, I test the difference in the mean beliefs of men and women ${ }^{7}$. There is no statistically significant difference in the beliefs of men and women for any type of paper. Men believe that a coauthored AER will increase their chance of receiving tenure by $12.1 \%$, and women by $12.2 \%$. Women believe that there are slightly lower returns to AER papers coauthored with senior faculty ( $8.8 \%$ versus $9.1 \%$ for men), but the difference is not statistically significant. These results suggest that, in this context, women are unaware of the true returns to coauthoring.

\subsubsection{Evidence on Sorting by Ability}

A second test of whether women know that they will receive less credit for papers and sort accordingly is to look at the correlation between propensity to coauthor and ability. I first test whether high ability women are less likely to coauthor than low ability women and then test for assortative matching among coauthors. I proxy for ability using the quality of journal that an individual's job market paper was published in. I assume that the job market paper is the first solo-authored paper an individual publishes after he or she graduates.

If women anticipate discrimination, ability and the fraction of one's papers that are coauthored will be negatively correlated. High ability women should be less likely to coauthor. In Figure 5.A I plot the coefficients $\hat{\beta}_{1}$ and $\hat{\beta}_{2}$ from estimating

$$
\text { FracC }_{i f s t}=\beta_{1} a_{i}+\beta_{2}\left(\text { fem }_{i} \times a_{i}\right)+\beta_{3} f_{e m_{i}}+\beta_{4} \text { TotPapers }_{i}+\theta_{f}+\theta_{s}+\theta_{t}+\epsilon_{i f s t}
$$

where $F r a c C A_{i f s t}$ is the fraction of person $i$ 's papers that are coauthored and $a_{i}$ is person $i$ 's ability (job market paper rank). If high ability women anticipate receiving less credit, we expect $\hat{\beta}_{2}<0$. In Figure 5.A, however, we see that ability is uncorrelated with the fraction of papers that are coauthored for both men and women: both estimates are precise zeros. There is no evidence that women along the ability distribution act strategically in their choice to coauthor versus solo author.

I also find no evidence that high ability women strategically coauthor with other women rather than men. Figure 5.B plots the results from equation 4 using the fraction of papers that are coauthored with women as the dependent variable. Women are more likely to coauthor with other women than men are but there is no sorting by ability.

While women do not seem to be sorting according to ability, it is possible that women tend to work with higher-ability coauthors who then receive more credit for a paper. I can

\footnotetext{
${ }^{7}$ Because the survey was anonymous, the answers can not be linked to the CV data. I can therefore only test for differences in means without controls.
} 
test for this by correlating a person's ability with that of his or her coauthors. While I do not have the job market paper information for all coauthors in the dataset, I can see where the coauthors were working at the time the individual went up for tenure. As a measure of average coauthor ability, I take the average school rank of all of an individual's pretenure coauthors. For example, if $i$ coauthors with $j$ and $k$ and $j$ works at the 5th-ranked institution and $k$ works at the 15th-ranked institution, the average ability of $i$ 's coauthors is 10. I correlate $i^{\prime}$ s ability with the average ability of her coauthors in Figure 6. The line of best fit is plotted controlling for number of coauthored and solo-authored publications, time until tenure, and field, institution, and tenure year fixed effects.

Men and women both sort positively on ability but women are more likely to collaborate with individuals at more highly-ranked institutions than men are. To see whether this can explain the results, I estimate

$$
\begin{aligned}
T_{i f s t}= & \beta_{1} S_{i}+\beta_{2}\left(\text { fem }_{i} \times S_{i}\right)+\beta_{3} C A_{i}+\beta_{4}\left(f e m_{i} \times C A_{i}\right)+\beta_{5} \operatorname{rank}_{i J} \\
& +\beta_{6}\left(C A_{i} \times \operatorname{rank}_{i J}\right)+\beta_{7}\left(\text { fem }_{i} \times C A_{i} \times \operatorname{rank}_{i J}\right)+\beta_{8}\left(\text { fem }_{i} \times \operatorname{rank}_{i J}\right) \\
& +\beta_{9} f_{e m}+\gamma^{\prime} Z_{i}+\theta_{f}+\theta_{s}+\theta_{t}+\epsilon_{i f s t}
\end{aligned}
$$

where $\operatorname{rank}_{i J}$ is the average institution rank of $i$ 's coauthors and all other variables are defined as before. The results are reported in Table 8 . If men receive more credit because they are coauthoring with lower ability women, $\hat{\beta}_{7}$ should be negative. However, $\hat{\beta}_{7}$ is close to zero, indicating that the ability of one's coauthor is not driving the tenure gap for coauthoring women.

\subsubsection{Returns to Top Papers}

For high ability women to receive no credit for their coauthored papers, employers would have to believe that there is no assortative matching by ability. Otherwise, employers would receive a signal that women who coauthor with high ability men are also high ability, and be more likely to promote them (see Appendix B for details). Figure 6 shows that assortative matching does occur, but it is possible that employers do not recognize this. I test for this by looking at how credit for top 5 publications is allocated. If employers know that there is assortative matching, they should believe that women coauthoring with high-ability men are also likely to be high ability. 
Table 10 shows the results from estimating

$$
\begin{aligned}
& T_{i f s t}=\beta_{1} T_{o p} S_{i}+\beta_{2}\left(f_{e m} \times T o p S_{i}\right)+\beta_{3} T_{o p C} A_{i}+\beta_{4}\left(f e m_{i} \times T o p C A_{i}\right)+\beta_{5} N_{o n T o p} S_{i} \\
& +\beta_{6} N_{o n T o p C A} A_{i}+\beta_{7}\left(f_{e m} \times N_{o n T o p} S_{i}\right)+\beta_{8}\left(f_{e m} \times N o n T o p C A_{i}\right)+\beta_{9} f_{e m}+\gamma^{\prime} Z_{i} \\
& +\theta_{f}+\theta_{s}+\theta_{t}+\epsilon_{i f s t}
\end{aligned}
$$

The female interaction terms are presented in the second column. Top $S_{i}$ and TopCA $A_{i}$ are the number of solo and coauthored papers that individual $i$ has published in a top 5 journal. Similarly, NonTop $S_{i}$ and $\operatorname{NonTopCA} A_{i}$ are the number of solo and coauthored papers the individual has published in non-top 5 journals. Note that power becomes an issue as (1) there are relatively few people publishing in the top 5 journals, and (2) cutting by gender means that there are even fewer women in each category. Still, Table 10 shows that coauthored papers published in a top 5 journal help women but still by less than they help men. The point estimate on the interaction term is negative and insignificant due to large standard errors, but it suggests that a coauthored publication in a top journal is associated with a $10 \%$ increase in tenure probability for women and a $15 \%$ increase for men. Non-top 5 coauthored papers do not have any positive influence on women's tenure probability. It seems that employers receive some signal when a woman publishes her coauthored papers in top journals which is at odds with the hypothesis that only low ability women coauthor with men.

Overall, there is little evidence that ability-based sorting is driving the results. If anything, employers seem to recognize that high ability men and women might work together and are therefore more likely to grant these women tenure. However, their tenure rate is still lower than that of high ability men.

\subsection{Preference-Based Sorting}

If women prefer to coauthor with senior faculty, we could reasonably expect that women would have lower tenure rates. Assuming senior faculty are more likely to be credited for a paper, the fact that most senior faculty are men would drive the correlation between coauthoring with a man and tenure. That is, women receive less credit because they enjoy coauthoring with senior faculty and these senior faculty are predominantly male.

To test whether women are more likely to coauthor with senior faculty and whether this can explain the results, I first estimate

$$
\text { MaleSr }_{i f s t}=\beta_{1} f e m_{i}+\beta_{2} T o t C A_{i}+\beta_{3} C A_{i}+\beta_{4} S_{i}+\gamma^{\prime} Z_{i}+\theta_{f}+\theta_{s}+\theta_{t}+\epsilon_{i f s t}
$$


where $M a l e S r_{i f s t}$ is either the number of fraction of male senior coauthors an individual has. The independent variables are defined as before with $\operatorname{Tot} C A_{i}$ being the number of coauthors an individual has worked with by the time s/he goes up for tenure. The results are presented in Column 1 of Table 9 . Women are not more likely to coauthor with senior men: the point estimate on $\mathrm{fem}_{i}$ in Column 1 is positive but small and insignificant.

As an additional check, I reestimate equation 2 but control for the fraction of a person's coauthors who are senior. The results are presented in Column 2 of Table 9. The seniority of women's coauthors does not explain the results. Controlling for coauthor composition, an additional coauthored paper increases a man's probability of tenure by 8 percentage points but a woman's by only 2 percentage points.

\subsection{Women Not Claiming Credit for Papers}

Women might be given less credit for their work if they are less likely to claim it as their own. For example, if women present less frequently than men, people might associate a paper with the male coauthor who presents it more. The survey discussed in Section 4.1.1 also asked individuals how many times per year they present their work and whether they are more or less likely to present their coauthored papers than their coauthor. Panel B of Table 7 shows that women do not report presenting their coauthored papers less frequently than their coauthors. Interestingly, though, women present their solo-authored papers fewer times per year than men do. It is possible that women do not "advertise" their work as much as men do and this leads to women receiving less recognition for their work in general. If this were true, though, women who solo author should also be less likely to receive tenure.

\subsection{Taste-Based Discrimination}

If some employers have a distaste for tenuring women, as in Becker (1971), we should see women who write solo-authored papers being denied tenure as well. If employers cannot plausibly deny a woman who solo-authored several well-published papers, however, they might be constrained to deny tenure only to those for whom they can make a reasonable case. If it can be argued that a woman who coauthors did little of the work, taste-based discrimination could help to explain the results as employers have an excuse for denying tenure to coauthoring women. However, as shown in Table 3, only women who coauthor with men have lower tenure rates. This would imply that employers have a particular distaste for tenuring women who coauthor with men, which seems unlikely. 


\section{Further Discussion: Are Things Improving and Where?}

As more women enter the economics profession, we would hope that any bias against women would begin to dissipate. As there are more examples of women doing high quality research, people might be less prone to innate biases. In Table 11, I reestimate equation 2 but interact the publication count variables with a linear time trend for the year an individual is expected to go up for tenure. The interaction coefficients are presented in column 2.

Women continue to receive less credit for coauthored work throughout the time period

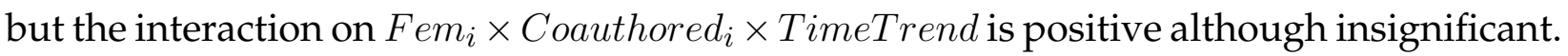
This provides some evidence that as more women enter the profession, they may be starting to receive more credit for joint work. Interestingly, the coefficient on the interaction

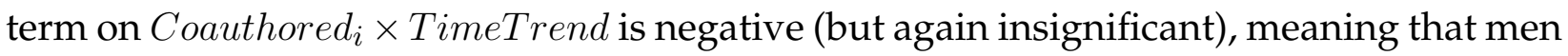
might begin to suffer a coauthor penalty in later years.

An additional question is whether some institutions are better than others. For example, women in the top schools might be viewed more favourably if people think that anyone who makes it to a top school must be good. On the other hand, if people think that there is affirmative action for women, especially at the top schools, women in such institutions might be viewed less favourably.

In Table 12, I report the results from estimating equation 2 interacting all paper count and gender variables with an individual's tenure institution ranking. I have inverted the rankings so that 30 is the highest rank and 1 the lowest. The interaction terms in column 2 show that women in higher-ranked schools receive slightly more credit for their coauthored papers while men receive slightly less credit. For women, moving up one spot in rankings improves the correlation between coauthoring and tenure by 0.001 percentage points. Moving from the lowest to the highest-ranked school is not enough to eliminate the negative correlation between coauthoring and tenure for women, but it does reduce the gap. These results could suggest that women at high-ranking schools are viewed more favourably and given more credit for joint work. Of course, I can not rule out the possibility that there is less gender bias at high-ranking schools, etc.

The results also show that men at lower-ranking schools benefit immensely from coauthoring: an additional coauthored paper is correlated with a 17.2 percentage point increase in tenure. This is in line with Ginther and Kahn's (2004) finding that men have many more publications, often coauthored, in lower ranked journals that they receive credit for. These publications are unlikely to count for much at the top schools. 


\section{Conclusion}

Women receive tenure at significantly lower rates than men in many academic fields. As discussed in the introduction, this phenomenon is not exclusive to academia. Several explanations have been put forward for the gap, but it persists even after accounting for observable characteristics such as fertility preferences and productivity.

This paper proposes an alternative explanation. I argue that women receive less credit for group work when employers can not perfectly observe their contribution. When signals are noisy, employers have to infer each worker's ability or productivity. Coauthored papers provide employers with a noisy signal. The fact that women who work specifically with men receive tenure at lower rates than comparable women who work alone or with other women suggests that gender enters into the employer's inference process. However, when employers receive clear signals, men and women are treated similarly. For example, men and women receive the same amount of credit for solo-authored papers, which

provide a clear signal of ability. Furthermore, when the uncertainty in a coauthored paper is resolved, as in sociology, women and men again receive the same amount of credit for joint work. I show that these results are not explained by sorting or women presenting their work less. I also argue that it is not due to blatant taste-based discrimination.

While a specific channel cannot be established with these data, being aware of this phenomenon is important in a world that is increasingly relying on group work for production. The tech industry, for example, prides itself on collaboration. In such maledominated fields, however, group work could result in fewer women moving up the career ladder if credit is not properly attributed. Further work is needed to determine why women seem to receive less credit for group work. 


\section{References}

[1] Antecol, Heather, Kelly Bedard, and Jenna Stearns. 2016. "Equal but Inequitable: Who Benefits from Gender-Neutral Tenure Clock Stopping Policies?" IZA Discussion Paper No. 9904.

[2] Becker, Gary. 1971. The Economics of Discrimination. Chicago: University of Chicago Press.

[3] Blau, Francine D. and Jed DeVaro. 2007. "New Evidence on Gender Differences in Promotion Rates: An Empirical Analysis of a Sample of New Hires." Industrial Relations, 46(3): 511-550.

[4] Ceci, Stephen J., Donna K. Ginther, Shulamit Kahn, and Wendy M. Williams. 2014. "Women in Academic Science: A Changing Landscape." Psychological Science in the Public Interest, 15(3): 1-67.

[5] Elmins, William, Robert Joyce, and Monica Costa Bias. 2016. "The Gender Wage Gap." Institute for Fiscal Studies Briefing Note 186.

[6] Ginther, Donna K. and Shulamit Kahn. 2004. "Women in Economics: Moving Up or Falling Off the Academic Career Ladder?" Journal of Economic Perspectives, 18(3): 193-214.

[7] Lazear, Edward P. and Kathryn L. Shaw. 2007. "Personnel Economics: The Economist's View of Human Resources." Journal of Economic Perspectives, 21(4): 91-114.

[8] MacLeod, W. Bentley. 2003. "Optimal Contracting with Subjective Evaluation." American Economic Review, 93(1): 216-240.

[9] Niederle, Muriel and Lise Vesterlund. 2007. "Do Women Shy Away From Competition? Do Men Compete Too Much?" Quarterly Journal of Economics, 122(3): 10671101.

[10] Pantelis Kalaitzidakis, Theofanis P. Mamuneas, and Thanasis Stengos. 2003. "Rankings of Academic Journals and Institutions in Economics." Journal of the European Economic Association, 1(6): 1346-1366.

[11] Prendergast, Canice. 1999. "The Provision of Incentives in Firms." Journal of Economic Literature, 104(5): 7-63. 


\section{Figures}

Figure 1: Total Papers AND Tenure

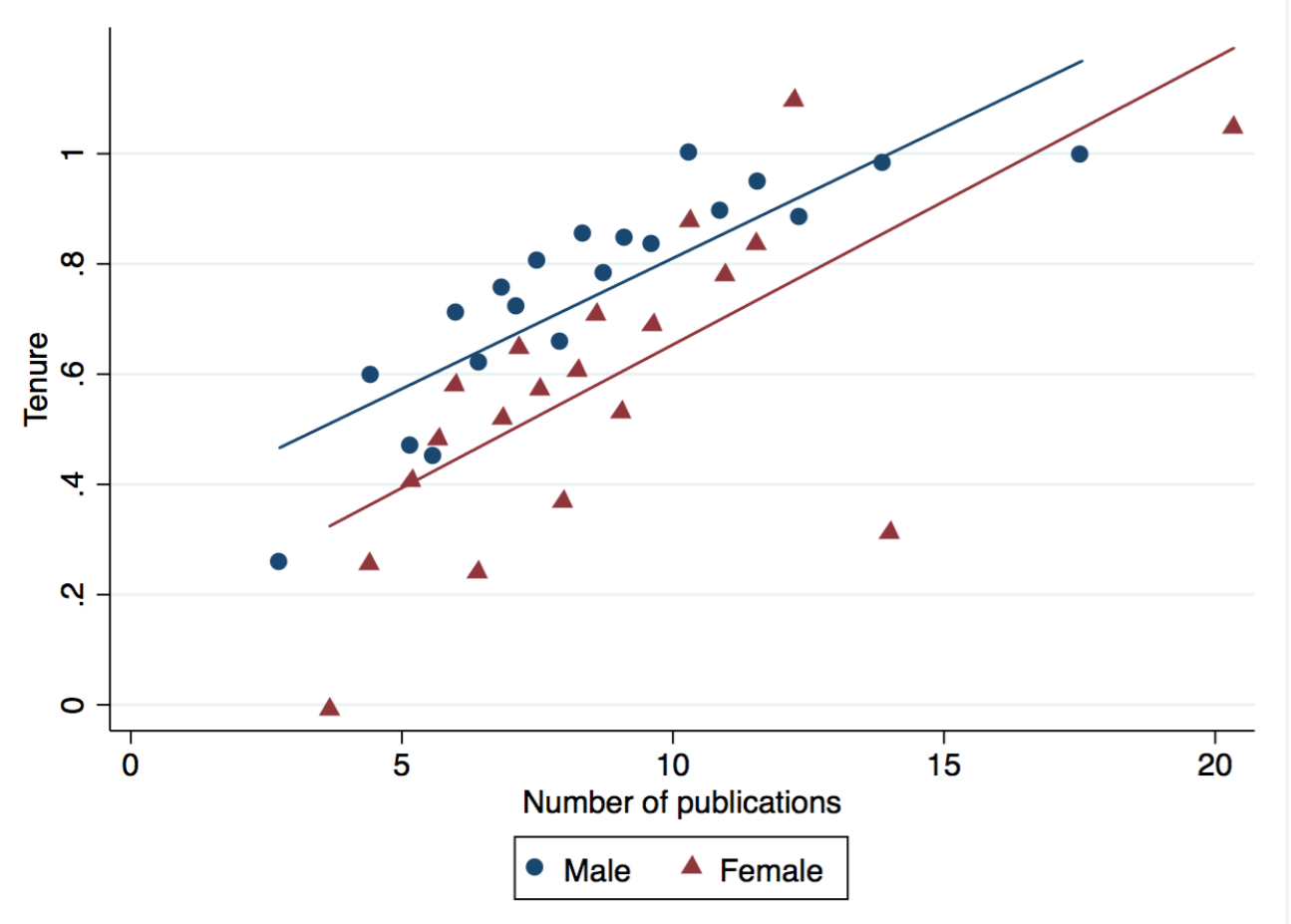

Notes: This figure is a binned scatterplot of the correlation between the total number of publications an individual has at the time they go up for tenure and the probability of receiving tenure. Both variables are residualized on the following controls before plotting: number of years it took to go up for tenure, average journal rank of pre-tenure publications, log citations, total coauthors, and tenure school, tenure year, and field fixed effects. The line of best fit using OLS is shown separately for men and women. The lines of best fit are estimated using the full sample $(\mathrm{N}=587)$ and have slopes of $\beta=0.050$ (s.e. $=0.014)$ for women and $\beta=0.047$ (s.e. $=0.005$ ) for men. The $y$-variable is a binary variable indicating whether an individual received tenure. Each dot represents the mean of approximately 30 observations along both dimensions. 
Figure 2: Solo Authored Papers and Tenure

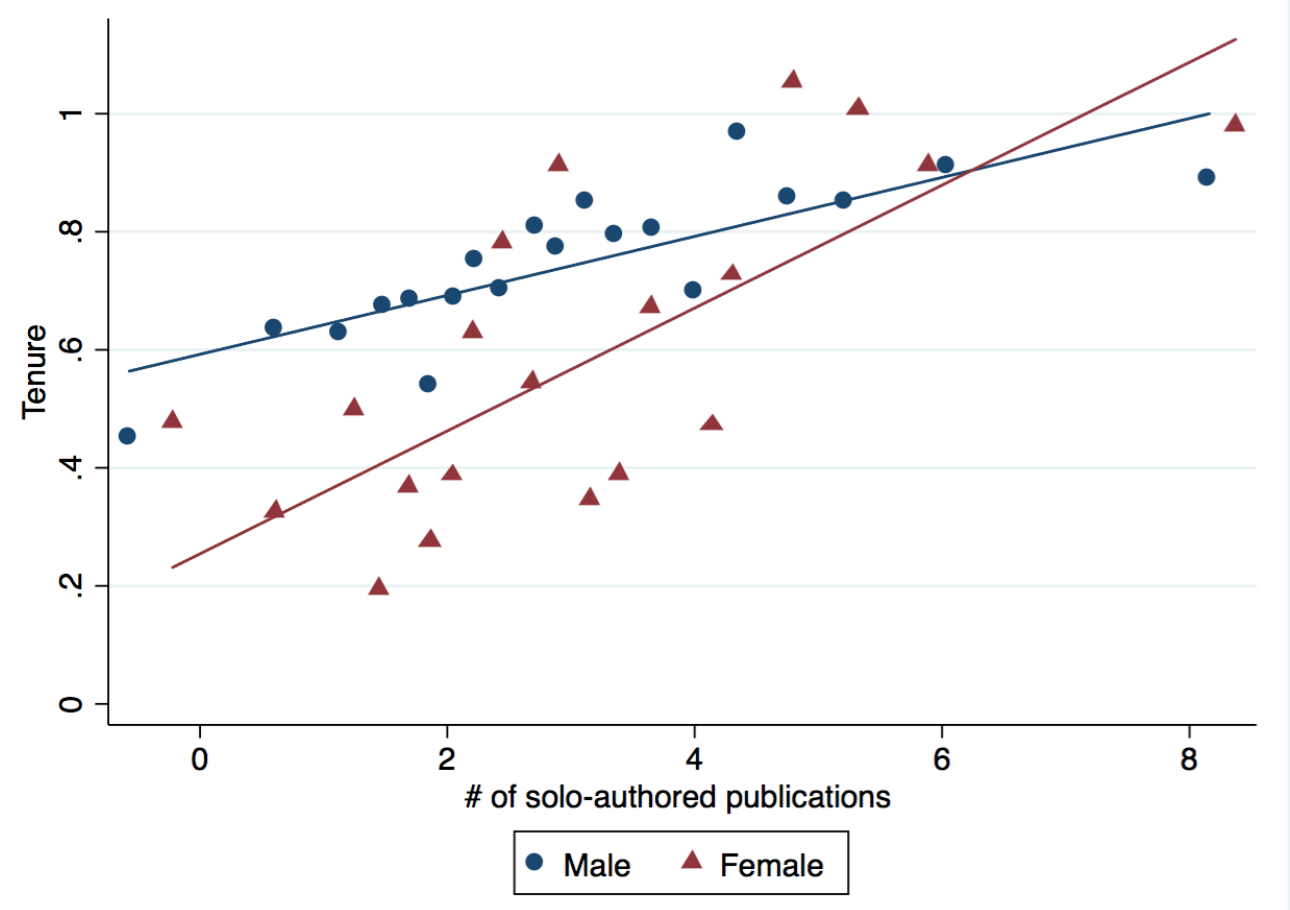

Notes: This figure is a binned scatterplot of the correlation between the number of solo-authored publications an individual has at the time they go up for tenure and the probability of receiving tenure. Both variables are residualized on the same controls in Figure 1. The lines of best fit are estimated using the sample of individuals who have at least one solo-authored publication $(\mathrm{N}=534)$ and have slopes of $\beta=0.106$ (s.e. $=0.020$ ) for women and $\beta=0.050$ (s.e. $=0.009$ ) for men. Each dot represents the mean of approximately 27 observations. 


\section{Figure 3: CoAuthored Papers and Tenure}

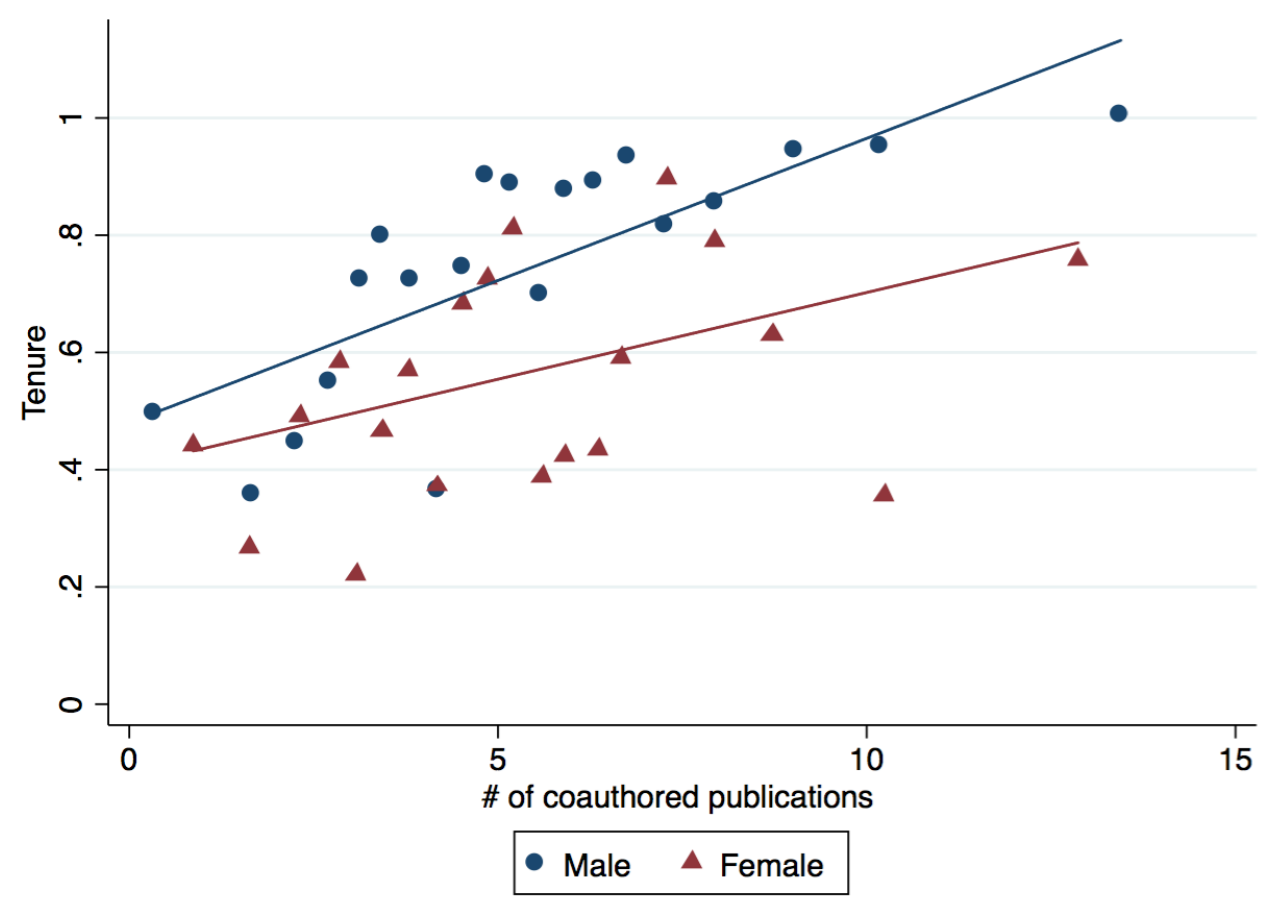

Notes: This is a binned scatterplot of the correlation between the number of coauthored publications an individual has at the time they go up for tenure and the probability of receiving tenure. Both variables are residualized on the same controls in Figure 1. The lines of best fit are estimated using the sample of individuals who have at least one solo-authored publication $(\mathrm{N}=529)$ and have slopes of $\beta=0.358$ (s.e. $=$ 0.014 ) for women and $\beta=0.050$ (s.e. $=0.006$ ) for men. Each dot represents the mean of approximately 26 observations. 


\section{Figure 4: Relationship Between Paper Composition and Tenure}

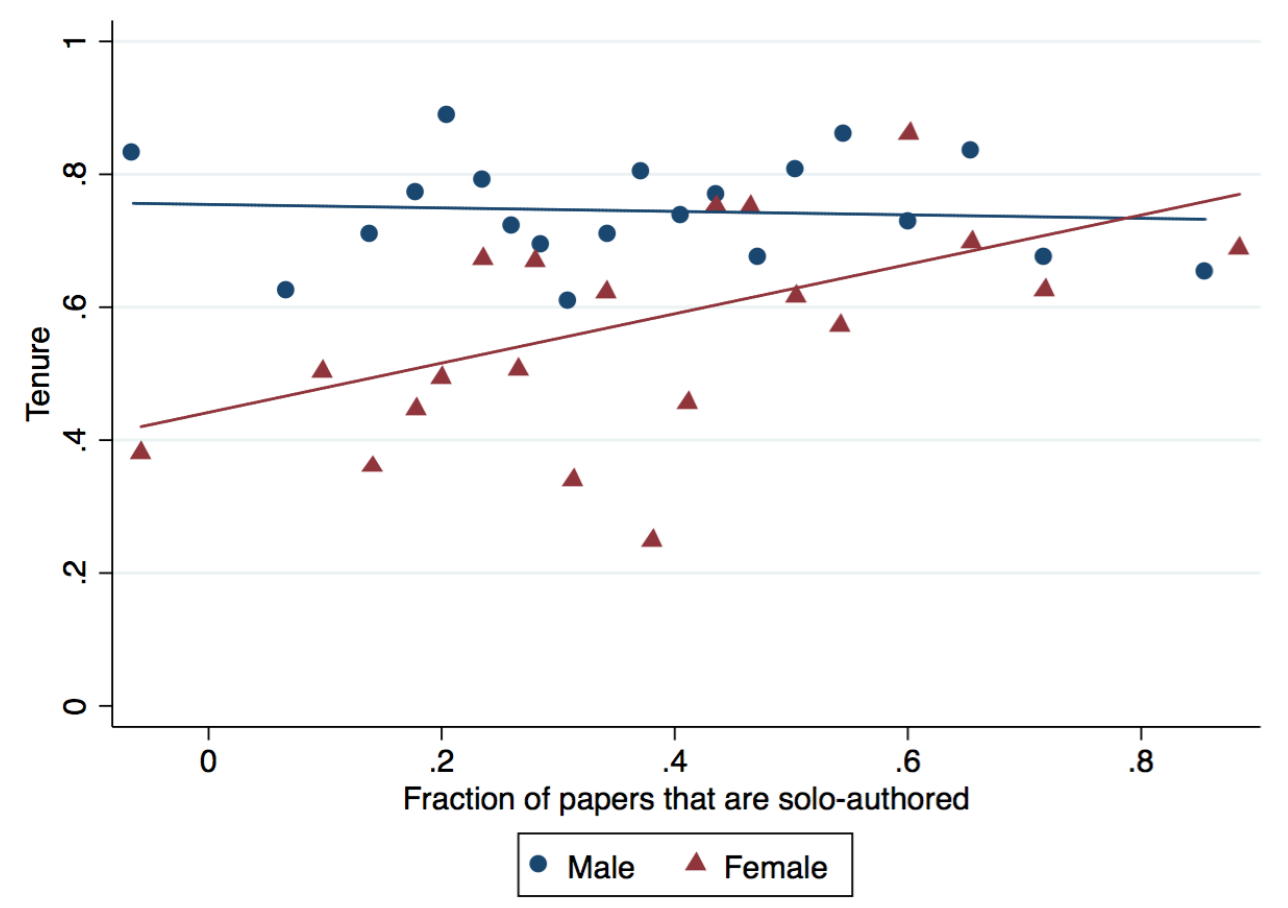

Notes: This figure is a binned scatterplot of the correlation between tenure and the fraction of an individual's papers that are solo-authored, split be gender. Both variables are residualized on the same controls in Figure 1. The line of best fit using OLS is shown separately for men and women. The lines of best fit are estimated using the full sample $(\mathrm{N}=587)$ and have slopes of $\beta=0.036$ (s.e. $=0.167)$ for women and $\beta=-0.028$ (s.e. $=0.078$ ) for men. The $y$-variable is a binary variable indicating whether an individual received tenure. Each dot represents the mean of approximately 30 observations along both dimensions. 


\section{Figure 5: ABILITY AND SORTING}
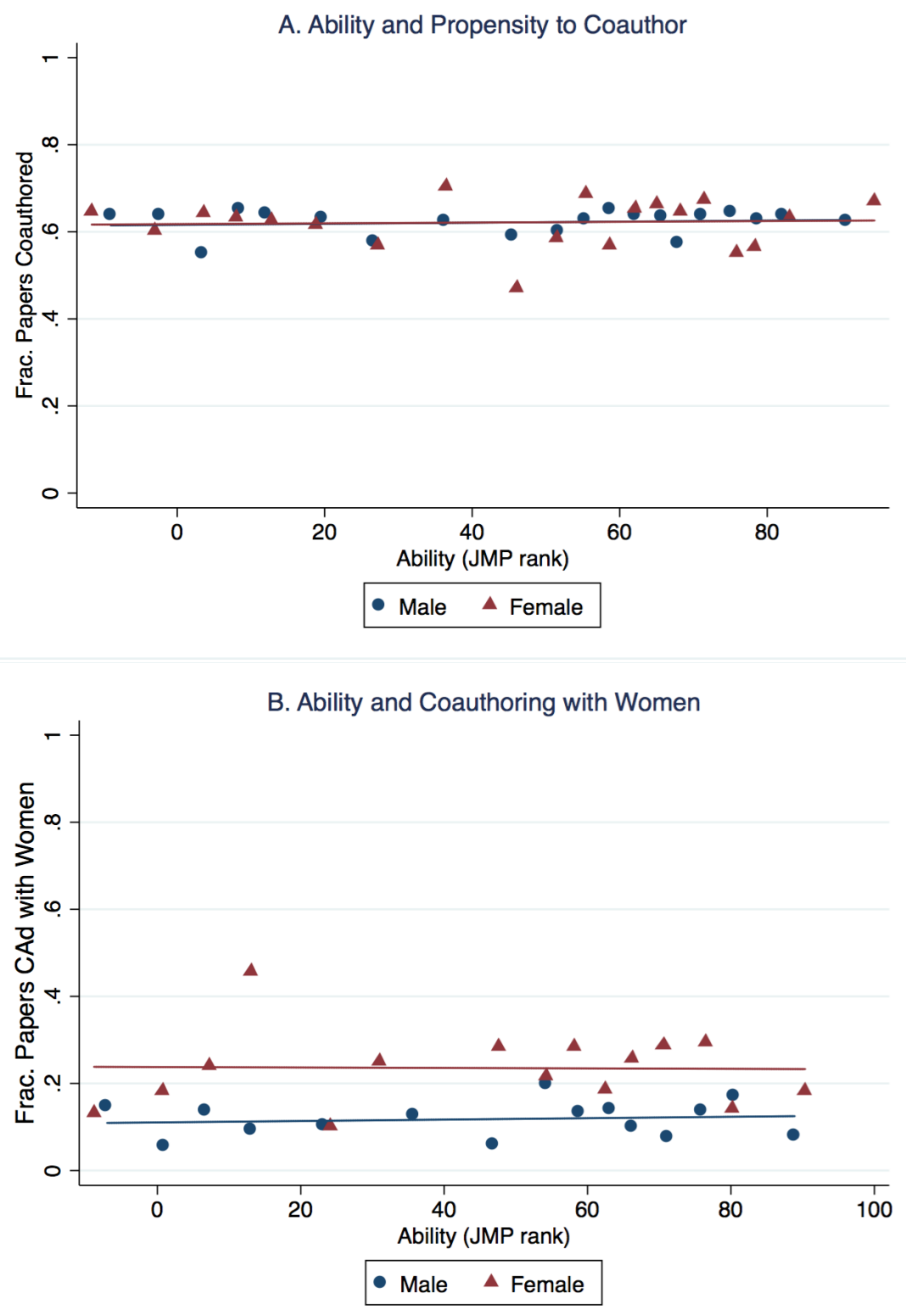

Notes: This binned scatterplot shows the correlation between an individual's ability and the propensity to coauthor (Fig. 5A) and the propensity to coauthor with women (Fig. 5B). I proxy for an individual's ability using the journal in which his or her job market paper is published in. Both variables are residualized on the following controls before plotting: total solo and coauthored papers, the number of years it took to go up for tenure, $\log$ citations, and tenure school, tenure year, and field fixed effects. The lines of best fit using OLS are shown separately for men and women. The estimates for Fig. 5A are $\beta=0.00002$ (s.e. $=0.0003$ ) for women and $\beta=-0.0001$ (s.e. $=0.0002$ ) for men. The estimates for Fig. 5B are $\beta=-0.00005$ (s.e. $=0.0008$ ) for women and $\beta=0.00016$ (s.e. $=0.0003$ ) for men. 


\section{Figure 6: Assortative Matching}

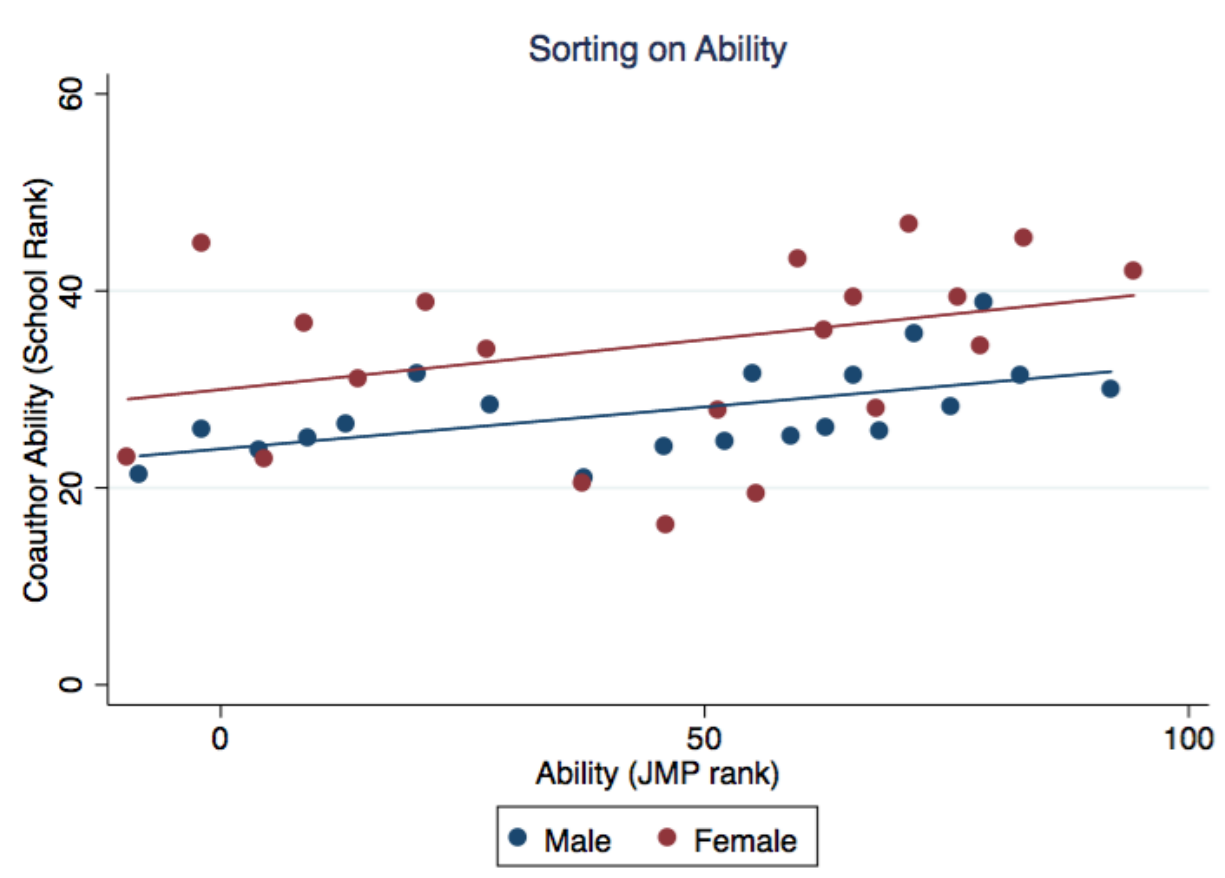

Notes: This binned scatterplot shows the correlation between an individual's ability, proxied by the journal in which their job market paper is published in, and their coauthor's ability, proxied by the average school rank of their coauthors. Both variables are residualized on the following controls before plotting: total solo and coauthored papers, the number of years it took to go up for tenure, log citations, and tenure school, tenure year, and field fixed effects. The line of best fit using OLS is shown separately for men and women. The lines of best fit are estimated on the full sample and have slopes of $\beta=-0.00005$ (s.e. $=0.0008$ ) for women and $\beta=0.0002$ (s.e. $=0.0003$ ) for men. 


\section{Tables}

TABle 1: SUMmary Statistics

\begin{tabular}{|c|c|c|c|c|}
\hline & Full & Male & Female & $\mathrm{p}$-value \\
\hline \multicolumn{5}{|l|}{ Panel A: } \\
\hline Tenure & $\begin{array}{c}0.70 \\
(0.46)\end{array}$ & $\begin{array}{c}0.75 \\
(0.43)\end{array}$ & $\begin{array}{c}0.53 \\
(0.50)\end{array}$ & 0.001 \\
\hline Years to tenure & $\begin{array}{c}6.8 \\
(1.9)\end{array}$ & $\begin{array}{c}6.6 \\
(1.6)\end{array}$ & $\begin{array}{c}7.1 \\
(1.8)\end{array}$ & 0.002 \\
\hline Total papers & $\begin{array}{c}8.5 \\
(4.0)\end{array}$ & $\begin{array}{c}8.6 \\
(4.1)\end{array}$ & $\begin{array}{c}8.1 \\
(3.4)\end{array}$ & 0.192 \\
\hline Solo-authored & $\begin{array}{c}3.0 \\
(2.3)\end{array}$ & $\begin{array}{c}3.0 \\
(2.3)\end{array}$ & $\begin{array}{c}3.1 \\
(2.3)\end{array}$ & 0.901 \\
\hline Coauthored & $\begin{array}{c}5.5 \\
(3.6)\end{array}$ & $\begin{array}{c}5.6 \\
(3.8)\end{array}$ & $\begin{array}{c}5.1 \\
(3.2)\end{array}$ & 0.132 \\
\hline \multicolumn{5}{|l|}{ Panel B: } \\
\hline Top 5 Solo & $\begin{array}{c}0.68 \\
(0.98)\end{array}$ & $\begin{array}{c}0.68 \\
(0.99)\end{array}$ & $\begin{array}{c}0.70 \\
(0.96)\end{array}$ & 0.788 \\
\hline Top 5 Coauthored & $\begin{array}{c}1.4 \\
(1.5)\end{array}$ & $\begin{array}{c}1.4 \\
(1.5)\end{array}$ & $\begin{array}{c}1.2 \\
(1.5)\end{array}$ & 0.176 \\
\hline \multicolumn{5}{|l|}{ Avg. Journal Rank: } \\
\hline All Pubs. & $\begin{array}{c}45.5 \\
(17.2)\end{array}$ & $\begin{array}{c}46.3 \\
(17.2)\end{array}$ & $\begin{array}{c}42.8 \\
(17.3)\end{array}$ & 0.037 \\
\hline Solo Pubs. & $\begin{array}{l}467.2 \\
(23.4)\end{array}$ & $\begin{array}{c}47.8 \\
(23.5)\end{array}$ & $\begin{array}{c}45.5 \\
(23.1)\end{array}$ & 0.348 \\
\hline Coauthored Pubs. & $\begin{array}{c}45.1 \\
(20.2)\end{array}$ & $\begin{array}{c}46.0 \\
(20.3)\end{array}$ & $\begin{array}{c}42.0 \\
(19.5)\end{array}$ & 0.052 \\
\hline \multicolumn{5}{|l|}{ Panel C } \\
\hline Total Unique CAs & $\begin{array}{c}5.0 \\
(3.1)\end{array}$ & $\begin{array}{c}5.0 \\
(3.0)\end{array}$ & $\begin{array}{c}4.9 \\
(3.2)\end{array}$ & 0.607 \\
\hline Frac. Sr Coauthors & $\begin{array}{c}0.30 \\
(0.32)\end{array}$ & $\begin{array}{c}0.30 \\
(0.30)\end{array}$ & $\begin{array}{c}0.31 \\
(0.32)\end{array}$ & 0.567 \\
\hline Frac. Fem Coauthors & $\begin{array}{c}0.14 \\
(0.23)\end{array}$ & $\begin{array}{c}0.11 \\
(0.19)\end{array}$ & $\begin{array}{c}0.26 \\
(0.30)\end{array}$ & 0.001 \\
\hline Observations & 574 & 441 & 133 & \\
\hline
\end{tabular}

This table presents summary statistics for the full sample and separately for men and women. All paper count variables (Total Papers, Solo-authored, Coauthored, and Top 5s) are the number of papers an individual had published at the time of tenure. 
TAble 2: Relationship Between Papers \& Tenure

\begin{tabular}{lccc}
\hline \hline Dep. Variable: Tenure & & & \\
& $(1)$ & $(2)$ & $(3)$ \\
& Probit & Probit & Probit \\
\hline Total papers & $0.058^{* * *}$ & & \\
& $(0.005)$ & & \\
Solo-authored & & $0.080^{* * *}$ & $0.075^{* * *}$ \\
& & $(0.011)$ & $(0.010)$ \\
Fem x Solo & & 0.009 & 0.013 \\
& & $(0.017)$ & $(0.016)$ \\
Coauthored & & $0.082^{* * *}$ & $0.077^{* * *}$ \\
& & $(0.009)$ & $(0.014)$ \\
Fem x Coauthored & & $-0.065^{* * *}$ & $-0.057^{* * *}$ \\
& & $(0.014)$ & $(0.014)$ \\
Avg Journal Rank & 0.003 & 0.004 & 0.004 \\
& $(0.001)$ & $(0.001)$ & $(0.001)$ \\
Total coauthors & & & 0.002 \\
& & & $(0.011)$ \\
Log Citations & & & -0.003 \\
& & & $(0.022)$ \\
Female & $-0.172^{* * *}$ & 0.100 & 0.051 \\
& $(0.039)$ & $(0.105)$ & $(0.101)$ \\
School FE & Yes & Yes & Yes \\
Tenure Year FE & Yes & Yes & Yes \\
Field FE & Yes & Yes & Yes \\
\hline Observations & 579 & 579 & 549 \\
Pseudo R2 & 0.307 & 0.349 & 0.362 \\
\hline \hline
\end{tabular}

This table shows the relationship between the number and types of papers an individual publishes and tenure. The dependent variable is a binary variable indicating whether the individual received tenure 6-7 years after being hired at the initial tenure institution. Total papers is the number of papers an individual had published by the time s/he went up for tenure. Solo-authored and Coauthored are the number of solo or coauthored papers s/he had published at the time of tenure. Avg. Journal Rank is the average journal rank of these pre-tenure publications, measured using the RePEc/IDEAS ranking. Tenure length is the number of years it took the individual to go up for tenure. Citations are from Google Scholar and measured at present. The equations are estimated using a probit model and the marginal probabilities calculated at the mean are displayed. Standard errors, reported in parentheses, are clustered by tenure institution. $\left({ }^{*}=\mathrm{p}<0.10,{ }^{* *}=\mathrm{p}<0.05,{ }^{* * *}=\mathrm{p}<0.01\right)$ 


\section{TABle 3: CoAuthor Gender}

\begin{tabular}{lcc}
\hline \hline Dep Var: Tenure & \multicolumn{2}{c}{$(1)$} \\
& Probit & $\begin{array}{c}\text { Probit } \\
\text { x Female }\end{array}$ \\
\hline Solo-authored & $0.064^{* * *}$ & 0.010 \\
Pubs. with only Fem CAs & $0.092^{* * *}$ & $(0.014)$ \\
& $(0.026)$ & $(0.027)$ \\
Pubs. with only Male CAs & $0.067^{* * *}$ & $-0.066^{* * *}$ \\
& $(0.013)$ & $(0.018)$ \\
Pubs. with M and F CAs & $0.084^{* *}$ & -0.048 \\
& $(0.031)$ & $(0.035)$ \\
Avg Journal Rank & 0.004 & \\
Total coauthors & $(0.001)$ & \\
& -0.001 & \\
Log Citations & $(0.009)$ & \\
& -0.001 & \\
Female & $(0.018)$ & \\
& 0.058 & \\
\hline Observations & $(0.096)$ & \\
\hline
\end{tabular}

This table presents the results of one regression where the interaction terms are displayed in the right-hand column. Pubs. with only Fem CAs is the number of publications an individual has in which all coauthors are female. Similarly, Pubs with only Male CAs and Pubs with M and F CAs are the number of publications with only male coauthors and with a mix of male and female coauthors respectively. The equations is estimated using a probit model and the marginal probabilities calculated at the mean are displayed. Standard errors, reported in parentheses, are clustered by tenure institution. $\left({ }^{*}=\mathrm{p}<0.10,{ }^{* *}=\mathrm{p}<0.05,{ }^{* * *}=\mathrm{p}<0.01\right)$ 


\section{TABLE 4: Sociology SUMmary STATISTICS}

\begin{tabular}{lccc}
\hline \hline & & & \\
& Men & Women & p-value \\
\hline Tenure & 0.752 & 0.776 & 0.547 \\
Total papers & $(0.433)$ & $(0.419)$ & \\
& 12.15 & 10.18 & 0.033 \\
Total coauthored & $(7.808)$ & $(5.726)$ & \\
& 6.409 & 5.959 & 0.567 \\
Solo papers & 5.745 & 4.224 & 0.003 \\
& $(4.451)$ & $(2.892)$ & \\
Time to tenure & 7.584 & 7.520 & 0.686 \\
\multirow{4}{*}{ Books } & $(1.607)$ & $(1.724)$ & \\
& 0.779 & 0.571 & 0.139 \\
\hline Observations & $(1.185)$ & $(0.799)$ & \\
\hline \hline
\end{tabular}

This table presents summary statistics for the full sample of sociologists and separately for men and women. All paper and book count variables (Total Papers, Solo-authored, Coauthored, and Top 5s) are the number of papers or books an individual had published at the time of tenure. 
Table 5: Sociology: Papers and Tenure

\begin{tabular}{lcc}
\hline \hline Dep Var: Tenure & $\begin{array}{c}\text { Probit } \\
(1)\end{array}$ & $\begin{array}{c}\text { Probit } \\
(2)\end{array}$ \\
\hline Total first author & $0.050^{* *}$ & \\
Fem $x$ First Author & $(0.017)$ & \\
& 0.026 & \\
Fraction first author & $(0.040)$ & \\
& & $0.403^{* * *}$ \\
Fem $x$ Frac. First Author & & $(0.043)$ \\
& & -0.042 \\
Solo papers & 0.008 & $0.172)$ \\
& $(0.006)$ & $(0.006)$ \\
Fem $x$ Total Solo & 0.002 & 0.007 \\
& $(0.011)$ & $(0.011)$ \\
Total Coauthored & $-0.010^{*}$ & 0.009 \\
& $(0.004)$ & $(0.007)$ \\
Fem $x$ Total CA & -0.020 & 0.001 \\
& $(0.017)$ & $(0.015)$ \\
Books & $0.063^{*}$ & 0.058 \\
& $(0.032)$ & $(0.035)$ \\
Book chapters & 0.007 & 0.005 \\
& $(0.013)$ & $(0.012)$ \\
Female & 0.026 & 0.010 \\
& $(0.114)$ & $(0.163)$ \\
School FE & Yes & Yes \\
Tenure Year FE & Yes & Yes \\
\hline Observations & 237 & 209 \\
\hline \hline
\end{tabular}

This table shows the relationship between the number and types of papers an individual publishes and tenure for a sample of sociologists. The dependent variable is a binary variable indicating whether the individual received tenure 6-7 years after being hired at the initial tenure institution. Total first author is the number of papers an individual is first author on while Fraction first author is the fraction of an individual's papers that $\mathrm{s} /$ he was first author on. The equations are estimated using a probit model and the marginal probabilities calculated at the mean are displayed. Standard errors, reported in parentheses, are clustered by tenure institution. $\left({ }^{*}=\mathrm{p}<0.10,{ }^{* *}=\mathrm{p}<0.05\right.$ $, * * *=\mathrm{p}<0.01)$ 
TABle 6: Robustness Checks

\begin{tabular}{|c|c|c|c|c|c|}
\hline & \multirow{2}{*}{$\begin{array}{c}\text { Attrition } \\
\text { Fac. List Sample } \\
\text { (1) }\end{array}$} & \multicolumn{2}{|c|}{ Journal Rankings } & \multicolumn{2}{|c|}{ Publication Count } \\
\hline & & $\begin{array}{l}\text { AER Equiv. } \\
\text { (2) }\end{array}$ & $\begin{array}{l}\text { Over Time } \\
\text { (3) }\end{array}$ & $\begin{array}{c}\text { Tenure }+1 \\
\text { (4) }\end{array}$ & $\begin{array}{c}\text { Tenure }+2 \\
\text { (5) }\end{array}$ \\
\hline \multirow[t]{2}{*}{ Solo-authored } & $0.058^{* * *}$ & $0.057^{* * *}$ & $0.072^{* * *}$ & $0.070^{* * *}$ & $0.069^{* * *}$ \\
\hline & $(0.011)$ & $(0.010)$ & $(0.010)$ & $(0.010)$ & $(0.011)$ \\
\hline \multirow[t]{2}{*}{ Coauthored } & $0.056^{* *}$ & $0.059^{* * *}$ & $0.077^{* * *}$ & $0.063^{* * *}$ & $0.053^{* * *}$ \\
\hline & $(0.017)$ & $(0.013)$ & $(0.014)$ & $(0.010)$ & $(0.008)$ \\
\hline \multirow[t]{2}{*}{ Fem $\times$ Coauthored } & $-0.047^{* * *}$ & $-0.060^{* * *}$ & $-0.055^{* * *}$ & $-0.052^{* * *}$ & $-0.045^{* *}$ \\
\hline & $(0.010)$ & $(0.013)$ & $(0.014)$ & $(0.013)$ & $(0.014)$ \\
\hline \multirow[t]{2}{*}{ Fem $\times$ Solo } & 0.019 & 0.015 & 0.011 & 0.009 & 0.016 \\
\hline & $(0.015)$ & $(0.013)$ & $(0.015)$ & $(0.014)$ & $(0.014)$ \\
\hline \multirow[t]{2}{*}{ Years to tenure } & $-0.019^{*}$ & $-0.053^{* * *}$ & $-0.053^{* * *}$ & $-0.050^{* * *}$ & $-0.050^{* * *}$ \\
\hline & $(0.008)$ & $(0.012)$ & $(0.010)$ & $(0.011)$ & $(0.011)$ \\
\hline \multirow[t]{2}{*}{ Total coauthors } & 0.005 & 0.009 & 0.002 & 0.011 & $0.016^{*}$ \\
\hline & $(0.011)$ & $(0.010)$ & $(0.011)$ & $(0.009)$ & $(0.008)$ \\
\hline \multirow[t]{2}{*}{ Log Citations } & -0.012 & 0.004 & 0.007 & -0.004 & -0.006 \\
\hline & $(0.015)$ & $(0.019)$ & $(0.021)$ & $(0.021)$ & $(0.022)$ \\
\hline \multirow[t]{2}{*}{ Avg Journal Rank } & $0.002^{*}$ & & $0.005^{* *}$ & $0.004^{* *}$ & $0.004^{* *}$ \\
\hline & $(0.001)$ & & $(0.001)$ & $(0.001)$ & $(0.001)$ \\
\hline AER Equiv. Solo & & $\begin{array}{c}0.028 \\
(0.063)\end{array}$ & & & \\
\hline \multirow[t]{2}{*}{ AER Equiv. CA } & & $0.298^{* *}$ & & & \\
\hline & & (0.111) & & & \\
\hline \multirow[t]{2}{*}{ Female } & 0.058 & 0.088 & 0.056 & 0.087 & 0.040 \\
\hline & $(0.067)$ & $(0.104)$ & $(0.100)$ & $(0.106)$ & $(0.122)$ \\
\hline School FE & Yes & Yes & Yes & Yes & Yes \\
\hline Tenure Year FE & Yes & Yes & Yes & Yes & Yes \\
\hline Field FE & Yes & Yes & Yes & Yes & Yes \\
\hline Observations & 278 & 467 & 551 & 549 & 543 \\
\hline
\end{tabular}

The dependent variable is an indicator for receiving tenure. Column 1 restricts the sample to those schools I received a historical faculty list from. Column 2 uses the number of AER-equivalents as individual has as the paper quality measure. This is broken up into the number of solo-authored AER-equivalents and coauthored AER-equivalents. Column 3 uses historical journal rankings to allow for rankings to change over time and to account for new journals entering. In Columns 4 and 5, I include papers that were published one and two years after an individual went up for tenure in the paper counts. Standard errors are clustered by tenure institution. $\left({ }^{*}=\mathrm{p}<0.10\right.$, $* *=\mathrm{p}<0.05, * * *=\mathrm{p}<0.01)$ 
TABLE 7: SURVEY RESUlTS

\begin{tabular}{lccc}
\hline \hline & $(1)$ & $(2)$ & $(3)$ \\
& Men & Women & p-value \\
\hline Panel A: Beliefs about Returns to Papers & & & \\
Coauthored AER & 12.1 & 12.2 & 0.939 \\
Coauthored AER, Sr. Faculty & 9.1 & 8.8 & 0.528 \\
Coauthored AER, Jr. Faculty & 13.3 & 13.4 & 0.796 \\
Solo Top Field & 8.0 & 8.2 & 0.669 \\
Coauthored Top Field & 6.3 & 6.8 & 0.223 \\
Panel B: Frequency of Presenting Papers & & & \\
Times Presented & 3.1 & 2.2 & 0.07 \\
Present More Freq. than CA & 0.37 & 0.44 & 0.20 \\
\hline Observations & 300 & 89 & \\
\hline \hline
\end{tabular}

This table presents the mean responses for men and women to the following survey questions: Panel A: "Suppose a solo authored AER increases your chance of receiving tenure by 15 percent. By how much do you think each of the following increases your change of receiving tenure?" Panel B: "How many times per year do you typically present your solo-authored papers? Are you more or less likely than your coauthors to present a joint paper?" The survey was conducted with a sample of academic economists currently working at a top 35 U.S. economics department. 
Table 8: Accounting for Sorting on Ability

\begin{tabular}{|c|c|c|}
\hline Dep Var: Tenure & (1) & $\begin{array}{c}(2) \\
\text { x Avg Coauthor Rank }\end{array}$ \\
\hline Solo-authored & $\begin{array}{c}0.081^{* * *} \\
(0.015)\end{array}$ & \\
\hline Fem $\times$ Solo & $\begin{array}{c}0.012 \\
(0.019)\end{array}$ & \\
\hline Coauthored & $\begin{array}{c}0.093^{* * *} \\
(0.017)\end{array}$ & $\begin{array}{l}-0.0003 \\
(0.0002)\end{array}$ \\
\hline Fem $x$ Coauthored & $\begin{array}{l}-0.053^{*} \\
(0.021)\end{array}$ & $\begin{array}{l}-0.0003 \\
(0.0002)\end{array}$ \\
\hline Female & $\begin{array}{c}0.108 \\
(0.128)\end{array}$ & \\
\hline Avg Journal Rank & $\begin{array}{l}0.004^{* *} \\
(0.001)\end{array}$ & \\
\hline Tenure Length & $\begin{array}{c}-0.056^{* * *} \\
(0.012)\end{array}$ & \\
\hline Log Citations & $\begin{array}{l}-0.031 \\
(0.024)\end{array}$ & \\
\hline Constant & & $\begin{array}{c}0.001 \\
(0.001)\end{array}$ \\
\hline School FE & Yes & \\
\hline Tenure Year FE & Yes & \\
\hline Field FE & Yes & \\
\hline Observations & 415 & \\
\hline
\end{tabular}

This table presents the results of one regression where the coefficients on the interaction terms (with Avg. Coauthor Rank) are displayed in Column 2. Avg Coauthor Rank is calculated by taking the mean of the school rank that an individual's coauthors are at when they wrote their joint paper. For example, if a person has two coauthors, one who is at the 5th-ranked school and one who is at the 10th-ranked school, Avg Coauthor Rank would be 7.5. Individuals who have no coauthored papers are not included in the sample. Standard errors are clustered by tenure institution. $\left({ }^{*}=\mathrm{p}<0.10\right.$, $\left.{ }^{* *}=\mathrm{p}<0.05, * * *=\mathrm{p}<0.01\right)$ 
TABLe 9: CoAuthor Seniority

\begin{tabular}{lcc}
\hline \hline Dep. Variable: & Frac. Sr Coauthors & Tenure \\
\hline Female & $(1)$ & $(2)$ \\
& OLS & Probit \\
Coauthored & 0.043 & 0.112 \\
& $(0.040)$ & $(0.124)$ \\
Solo-authored & 0.019 & $0.078^{* * *}$ \\
& $(0.014)$ & $(0.015)$ \\
Fem x Solo & $-0.023^{* *}$ & $0.070^{* * *}$ \\
& $(0.008)$ & $(0.010)$ \\
Fem x Coauthored & & 0.005 \\
& & $(0.018)$ \\
Frac. Sr Coauthors & & $-0.059^{* * *}$ \\
& & $(0.014)$ \\
Fem x Frac. Sr Coauthors & & -0.131 \\
& & $(0.072)$ \\
Total coauthors & & 0.040 \\
& & $(0.102)$ \\
Years to tenure & -0.014 & 0.005 \\
& $(0.011)$ & $(0.012)$ \\
Avg Journal Rank & 0.005 & $-0.038^{* * *}$ \\
& $(0.009)$ & $(0.010)$ \\
Log Citations & 0.001 & $0.005^{* * *}$ \\
& $(0.001)$ & $(0.001)$ \\
School FE & -0.016 & -0.010 \\
Tenure Year FE & $(0.013)$ & $(0.022)$ \\
Field FE & Yes & Yes \\
\hline Observations & Yes & Yes \\
\hline \hline
\end{tabular}

The dependent variable in Column 1 is the fraction of an individual's coauthors that are senior (full professors). The dependent variable in Column 2 is the binary tenure outcome. Column 1 is estimated using OLS and Column 2 uses probit. Standard errors are clustered by tenure institution. $\left({ }^{*}=\mathrm{p}<0.10,{ }^{* *}=\mathrm{p}<0.05,{ }^{* * *}=\mathrm{p}<0.01\right)$ 
TABle 10: Paper SPlit by Top 5

\begin{tabular}{lcc}
\hline \hline Dep Var: Tenure & \multicolumn{2}{c}{$(1)$} \\
& Top 5 & Non-Top 5 \\
\hline Solo & $0.135^{* * *}$ & $0.057^{* * *}$ \\
& $(0.027)$ & $(0.011)$ \\
Coauthored & $0.127^{* * *}$ & $0.055^{* * *}$ \\
& $(0.025)$ & $(0.013)$ \\
Female x Solo & -0.033 & 0.028 \\
& $(0.039)$ & $(0.023)$ \\
Female x Coauthored & -0.036 & $-0.063^{* * *}$ \\
& $(0.032)$ & $(0.015)$ \\
Female & 0.047 & \\
& $(0.111)$ & \\
Total coauthors & 0.008 & \\
& $(0.010)$ & \\
Log Citations & -0.010 & \\
& $(0.017)$ & \\
Years to tenure & $-0.052^{* * *}$ & \\
& $(0.010)$ & \\
\hline School FE & Yes & \\
Tenure Year FE & Yes & \\
Field FE & Yes \\
\hline Observations & 535 \\
\hline \hline
\end{tabular}

This table presents the results of one regression where Column 1 shows the coefficients on the number of top 5 solo and coauthored papers and Column 2 shows the coefficients on the number of non-top 5 solo and coauthored papers. Top 5 papers are those published in the American Economic Review, Econometrica, the Journal of Political Economy, Quarterly Journal of Economics, or the Review of Economic Studies. Standard errors are clustered by tenure institution. $\left({ }^{*}=\mathrm{p}<0.10,{ }^{* *}=\mathrm{p}<0.05\right.$ $\left.{ }^{* * *}=\mathrm{p}<0.01\right)$ 
TABle 11: Results OVER TIME

\begin{tabular}{|c|c|c|}
\hline & (1) & $\begin{array}{c}\text { (2) } \\
x \text { Time Trend }\end{array}$ \\
\hline Solo-authored & $\begin{array}{c}0.099 * * \\
(0.037)\end{array}$ & $\begin{array}{c}-0.001 \\
(0.001)\end{array}$ \\
\hline Fem $\times$ Solo & $\begin{array}{c}0.066 \\
(0.066)\end{array}$ & $\begin{array}{c}-0.001 \\
(0.002)\end{array}$ \\
\hline Coauthored & $\begin{array}{c}0.130^{* * *} \\
(0.032)\end{array}$ & $\begin{array}{l}-0.002 \\
(0.001)\end{array}$ \\
\hline Fem $\times$ Coauthored & $\begin{array}{c}-0.118^{*} \\
(0.051)\end{array}$ & $\begin{array}{c}0.002 \\
(0.001)\end{array}$ \\
\hline Female & $\begin{array}{l}-0.003 \\
(0.100)\end{array}$ & \\
\hline Total Coauthors & $\begin{array}{c}0.001 \\
(0.009)\end{array}$ & \\
\hline Log Citations & $\begin{array}{c}0.017 \\
(0.023)\end{array}$ & \\
\hline Constant & & $\begin{array}{c}0.009 \\
(0.006)\end{array}$ \\
\hline
\end{tabular}

This table shows the results from one regression where solo and coauthored papers are interacted with a linear time trend in the year an individual is expected to go up for tenure. The coefficients in Column 2 show are the interactions between paper types, author gender, and the time trend. Standard errors are clustered by tenure institution. $\left({ }^{*}=\mathrm{p}<0.10,{ }^{* *}=\mathrm{p}<0.05,{ }^{* * *}=\mathrm{p}<0.01\right)$ 
TABLE 12: INTERACTION W/ SCHOOL RANK

\begin{tabular}{lcc}
\hline \hline & \multicolumn{2}{c}{$\begin{array}{c}(1) \\
\text { Probit } \\
\text { x School Rank }\end{array}$} \\
\hline Solo-authored & $0.091^{*}$ & -0.0002 \\
Coauthored & $(0.042)$ & $(0.001)$ \\
Fem x Solo & $0.172^{* * *}$ & $-0.001^{*}$ \\
& $(0.041)$ & $(0.001)$ \\
Fem x Coauthored & 0.070 & -0.001 \\
& $(0.063)$ & $(0.001)$ \\
Avg Journal Rank & $0.154^{* *}$ & $0.001^{*}$ \\
& $(0.048)$ & $(0.001)$ \\
Female & 0.112 & \\
Years to tenure & $(0.106)$ & \\
Total coauthors & $-0.048^{* * *}$ & \\
Log Citations & $(0.010)$ & \\
Constant & 0.004 & \\
& $(0.010)$ & \\
\hline Observations & 0.001 & \\
\hline
\end{tabular}

This table shows the results from one regression where solo and coauthored papers are interacted with the ranking of an individual's tenure institution. SchoolRank is defined such that 30 is the highest-ranked school and 1 is the lowest-ranked. The coefficients in Column 2 show are the interactions between paper types, author gender, and school rank. Standard errors are clustered by tenure institution. $\left({ }^{*}=p<0.10,{ }^{* *}=p<0.05\right.$ ,$\left.^{* * *}=\mathrm{p}<0.01\right)$ 


\section{Appendix A}

\section{List of institutions included in analysis}

Received faculty list: Brown, Columbia, Duke, Michigan State University, NYU, Northwestern, Ohio State University, Penn State, UC Berkeley, UC San Diego, UCLA, University of Virginia, University of Maryland, University of Michigan, University of Minnesota, University of Pennsylvania, University of Wisconsin-Madison

No faculty list: Boston College, Boston University, California Institute of Technology, Cornell, Harvard, MIT, Princeton, Stanford, University of Southern California, University of Chicago, University of Texas - Austin, University of Rochester, Yale

\section{Appendix B}

This simple matching example illustrates how women's knowledge of the returns to coauthoring affects their authorship decisions. It describes the contexts in which we would (1) expect high ability men and women to collaborate, making the decision not to promote collaborating women sub-optimal, and (2) expect low ability women and high ability men to collaborate, making the decision not to tenure collaborating women optimal. The model abstracts from the employer's problem, assuming that employers want to promote anyone who is high ability and not promote anyone who is low ability, and focuses on how knowledge of the true returns to coauthoring could lead to sorting among workers.

\section{Setup}

There are two types of agents: employers and workers. Workers produce papers and can choose whether to work alone or to collaborate. The quality of the paper depends on the worker's ability, as well as that of the collaborator if the worker collaborates. The employer uses the quality of the paper as a signal to infer the worker's type so the worker wants to maximize the quality of the paper subject to production costs.

Workers are either high or low ability, $\left(a_{i} \in\{h, l\}\right)$, and belong to an identifiable group, men or women $\left(g_{i} \in\{m, w\}\right)$. I make the simplifying assumption that workers know each other's ability but the employer does not. As mentioned earlier, workers choose whether to work alone or collaborate, $c_{i} \in\{S, C A\}$, and are trying to maximize the quality of the paper. Paper quality is a function of each collaborator's type: $f\left(a_{i, g}\right)$ if $c=S$ and 
$f\left(a_{i, g}, a_{j, g}\right)$ if $c=C A$. I assume that high ability men and women produce the same quality of papers $\left(f\left(h_{w}\right)=f\left(h_{m}\right)\right)$ as do low ability men and women.

The payoffs to producing solo and coauthored papers respectively are

$$
\begin{gathered}
\pi_{i, S}=f\left(a_{i, g}\right)-\kappa_{S} \\
\pi_{i, C A}=f\left(a_{i, g}, a_{j, g}\right)-\kappa_{C A}
\end{gathered}
$$

where the costs of producing solo and coauthored papers, $\kappa_{S}$ and $\kappa_{C A}$, are assumed to be constants with $\kappa_{S} \neq \kappa_{C A}$.

\section{Assortative Matching with Equal Credit for Papers}

Consider a woman's final payoff to producing a solo-authored paper and a paper coauthored with a man:

$$
\begin{aligned}
& \pi_{S}=f\left(a_{w}\right)-\kappa_{S} \\
& \pi_{C A}=f\left(a_{w}, a_{m}\right)-\kappa_{C A}
\end{aligned}
$$

If types are complimentary, the quality of a paper is higher when high ability women work with high ability men:

$$
f\left(h_{w}, h_{m}\right)-f\left(l_{w}, h_{m}\right)>f\left(h_{w}, l_{m}\right)-f\left(l_{w}, l_{m}\right)
$$

In this case, a high ability woman is willing to offer a high ability man $f\left(h_{w}, h_{m}\right)-$ $f\left(h_{w}, l_{m}\right)$ to collaborate, while a low ability woman is willing to offer $f\left(l_{w}, h_{m}\right)-f\left(l_{w}, l_{m}\right)$. Inequality (10) states that $f\left(l_{w}, h_{m}\right)-f\left(l_{w}, l_{m}\right)<f\left(h_{w}, h_{m}\right)-f\left(h_{w}, l_{m}\right)$, meaning that high ability women can outbid low types. Therefore, high types will coauthor and low types will coauthor as long as the costs of coauthoring do not outweigh the benefits. For high types to work together, the following conditions must be true for both men and women:

$$
\begin{aligned}
& f\left(h_{w}, h_{m}\right)-f\left(h_{w}\right) \geq \kappa_{C A}-\kappa_{S} \\
& f\left(h_{w}, h_{m}\right)-f\left(h_{m}\right) \geq \kappa_{C A}-\kappa_{S}
\end{aligned}
$$

If at least one of (11) or (12) does not hold, there will be no coauthoring between men and women. Because we assume that $f\left(h_{w}\right)=f\left(h_{m}\right)$, if (11) does not hold, neither does (12) and vice versa. Since $f\left(h_{w}, h_{m}\right)>f\left(h_{w}, l_{m}\right)=f\left(l_{w}, h_{m}\right)$, high ability workers who do not want to collaborate with other high ability workers will not want to collaborate with low 
ability workers either.

Thus, in the case of assortative matching in which men and women have the same returns to papers, men and women will only coauthor with the same ability type. A woman coauthoring with a high ability man thus provides the employer with a signal that she too is a high type, and women who coauthor with men should be no less likely to receive tenure than high ability men. Note that this would also be the case if women received less credit for papers but did not know it. That is, if $f_{w}\left(h_{w}, h_{m}\right)<f_{m}\left(h_{w}, h_{m}\right)$ but women believe these to be equal.

\section{Assortative Matching with Unequal Credit for Papers}

Now assume that women receive less credit for their collaborative work and that they know this. Specifically, let the payoff to a woman who coauthors with a man be $\hat{\pi}_{C A}=$ $\beta f\left(m_{a}, w_{a}\right)-\kappa_{C A}$ where $\beta<1$. The payoffs to coauthoring for high types are now

$$
\begin{gathered}
\text { Woman }: \beta f\left(h_{w}, h_{m}\right)-f\left(h_{w}\right)>\kappa_{C A}-\kappa_{S} \\
\text { Man }: f\left(h_{w}, h_{m}\right)-f\left(h_{m}\right)>\kappa_{C A}-\kappa_{S}
\end{gathered}
$$

If both ((13)) and (14)) hold, we are back in the case of assortative matching. Both groups are willing to collaborate and high type women are able to outbid low type women. However, if $\beta$ is sufficiently small, ((13)) becomes less likely to hold and high ability women will choose to solo author.

Since payoffs between men and women are now different, there are some cases in which high-ability men and low-ability women might collaborate. In particular, highability men will be willing to coauthor with low-ability women if

$$
f\left(l_{w}, h_{m}\right)-f\left(m_{h}\right)>\kappa_{C A}-\kappa_{S}
$$

and low-ability women will coauthor if

$$
\beta f\left(l_{w}, h_{m}\right)-f\left(w_{l}\right)>\kappa_{C A}-\kappa_{S}
$$

Note that $\beta f\left(h_{w}, h_{m}\right)-f\left(h_{w}\right)<\kappa_{C A}-\kappa_{S}$ does not imply that $\beta f\left(l_{w}, h_{m}\right)-f\left(l_{w}\right)<$ $\kappa_{C A}-\kappa_{S}$ since $f\left(h_{w}\right)>f\left(l_{w}\right)$. Therefore, if $\beta f\left(l_{w}, h_{m}\right)$ is sufficiently larger than $f\left(l_{w}\right)$ for low-ability women (that is, the paper is greatly improved with the help of a coauthor), then we might still see low-type women wanting to coauthor with men. If the cost savings of coauthoring are large enough and if coauthoring with a low type does not reduce the 
quality of the paper, men will still be willing to coauthor with low ability women. Of course, many high-ability men will choose to coauthor with other high-ability men rather than a low-ability woman. The purpose of this example is to illustrate the circumstances under which we would see women sorting into solo and coauthoring by ability. For this, we need to assume that at least some high-ability men must coauthor with a woman.

Overall, if women do not know that they have lower returns to coauthoring, we will see assortative matching. In this case, employers who believe a man to be high ability should also believe his female collaborator is high ability. Denial of tenure in this case is sub-optimal. However, if women know the returns to coauthoring, high ability women will solo-author or work with other high-ability women and tenure denial is rational.

This example only considered two types of workers, high and low ability. Extending it to more types does not change the results. Assortative matching will ensure that workers will always match with workers of their type. When women know the true returns to coauthoring, the highest ability women will work alone and any male/female matching will require that the woman is slightly lower ability than the man. 